\title{
The Use of Electric Fields for Edible Coatings and Films Development and Production: A Review
}

\author{
Bartolomeu W. S. Souza $\cdot$ Miguel A. Cerqueira $\cdot$ \\ José A. Teixeira $\cdot$ António A. Vicente
}

Received: 6 January 2010/Accepted: 13 October 2010/Published online: 30 October 2010

(C) Springer Science+Business Media, LLC 2010

\begin{abstract}
Edible films and coatings can provide additional protection for food, while being a fully biodegradable, environmentally friendly packaging system. A diversity of raw materials used to produce edible coatings and films are extracted from marine and agricultural sources, including animals and plants. Electric fields processing holds advantage in producing safe, wholesome and nutritious food. Recently, the presence of a moderate electric field during the preparation of edible coatings and films was shown to influence their main properties, demonstrating its usefulness to tailor edible films and coatings for specific applications. This manuscript reviews the main aspects of the use of electric fields in the production of edible films and coatings, including the effect in their transport and mechanical properties, solubility and microstructure.
\end{abstract}

Keywords Edible coatings - Electric fields - Edible films $\cdot$ Permeability $\cdot$ Wettability $\cdot$ Microstructure

\section{Edible Films and Coatings: Concept, Function and Composition}

\section{Concept}

Edible coatings and edible films are the two terms used in food packaging, sometimes without any distinction. However, it is important to make such distinction: a "film" is a

B. W. S. Souza - M. A. Cerqueira · J. A. Teixeira .

A. A. Vicente $(\square)$

IBB-Institute for Biotechnology and Bioengineering, Centre of Biological Engineering, Universidade do Minho, Campus de Gualtar, 4710-057 Braga, Portugal

e-mail: avicente@deb.uminho.pt thin skin formed e.g., through casting of the biopolymer solution prepared separately from the food that is later applied to it, while a coating can be a suspension or an emulsion applied directly on the surface of the food, leading to the subsequent formation of a film.

Edible films and coatings have received considerable attention in recent years because of their advantages over synthetic films. The main advantage of edible films over traditional synthetics is that they can be consumed with the packaged products. There is no package to dispose of, and even if the films are not consumed, they could still contribute to the reduction in environmental pollution once they are biodegradable. In fact, edible films are produced exclusively from renewable, edible ingredients and therefore are anticipated to degrade more readily than polymeric materials [1]. The potential of edible films to control water transfer and to improve food quality and shelf life has raised increasing attention from researchers and industry [2]. However, the search for new renewable materials from natural sources is an important task when new functionalities are sought and/or new uses for less noble materials must be enforced for economical and environmental reasons.

\section{Function}

The aim is to produce natural biopolymer-based materials with specific properties (adequate mass transfer-e.g., water vapor, $\mathrm{CO}_{2}$ and $\mathrm{O}_{2}$-mechanical, surface-particularly important in the case of coatings-and optical properties), which may be eaten together with the food [3]. Those properties will be resulting from an adequate combination of materials, processing and application methods.

Edible films and coatings can be utilized in the food industry to meet challenges associated with long-term 
quality, market safety, nutritional value and economic production cost. With regard to the fresh products industry, the potential benefits of using edible films and coatings include the following:

1. Providing a moisture barrier on the surface of the product thus minimizing the problem of moisture loss. Moisture loss during postharvest storage of fresh products leads to weight loss and changes in texture, flavor and appearance;

2. Providing sufficient gas barriers for controlling gas exchange between the fresh product and its surrounding atmosphere, e.g., slowing down respiration and delaying deterioration. The gas-barrier function could in turn retard enzymatic oxidation and protect the fresh product from e.g., browning and texture softening during storage;

3. Restricting the exchange of volatile compounds between the fresh product and its surrounding environment, again by providing gas barriers, thus preventing both the loss of natural volatile flavor compounds and color components from the fresh product and the contamination with different odors (e.g., during refrigerated storage);

4. Protecting the product from physical damage caused by mechanical impact, pressure, vibrations and other mechanical factors (to a limited extent);

5. Acting as carriers of functional ingredients, such as antimicrobial and antioxidant agents, nutraceuticals, and color and flavor ingredients for reduction in microbial loads, delaying oxidation and discoloration and improving the overall quality [4].

\section{Composition}

A great diversity of materials is used to produce edible coatings and films, but most of them can be included in one of three categories: polysaccharides, proteins and lipids.

\section{Polysaccharides}

Polysaccharides that have been evaluated or used to form coatings/films include starch and starch derivatives, cellulose derivatives, alginates, carrageenan, various plant and microbial gums, chitosan and pectinates [5, 6].

Polysaccharides are generally very hydrophilic, resulting in poor water vapor and gas-barrier properties. Although coatings by polysaccharide polymers may not provide a good water vapor barrier, these coatings can act as sacrificing agents retarding moisture loss from food products $[7,8]$.

Polysaccharides can exhibit a neutral charge (e.g., acetate esters, methyl ethers, other neutral sugars), negative charge (e.g., carboxylate, sulfate groups) or positive charge (e.g., amino groups) due to the presence of various chemical groups attached to individual monosaccharide units. All of these structural features of polysaccharides contribute to their differences in solubility, synergy or incompatibility with each other or with other ingredients (e.g., proteins, minerals, acids and lipids), thickening, gelling and emulsifying properties. These differences in behavior will ultimately affect polysaccharides' coating- or film-forming properties [9].

\section{Proteins}

A variety of proteins from natural sources (such as casein, whey, soy, corn zein, collagen, wheat gluten, keratin and egg albumen) have been tested in the production of edible films [10].

Properties of protein-based films depend on various factors, such as the source of protein, $\mathrm{pH}$ of protein solution, type and concentration of plasticizers, the preparation conditions and substances incorporated into the film-forming solutions. Protein-based films generally have good mechanical properties due to the interactions between protein chains via disulfide (S-S) covalent bonding, hydrogen bonding, electrostatic forces and hydrophobic interactions [11]. Protein-based films also have good oxygen-barrier properties in low relative humidity, but have high water absorptivity, owing to the hydrophilicity of protein molecules and to the significant amounts of hydrophilic plasticizers, such as glycerol and sorbitol, usually incorporated into films to impart adequate flexibility [12].

\section{Lipids}

Edible lipids including neutral lipids, fatty acids, waxes and resins are the traditional coating materials for fresh products. Wax- and oil-based coatings include paraffin wax, candelilla wax, beeswax, carnauba wax, polyethylene wax and mineral oil [13].

Lipid coatings are mainly used for their hydrophobic properties, which make them good barriers to moisture loss. In addition to preventing water loss, lipid coatings have been used to reduce respiration, thereby extending shelf life, and to improve appearance by generating a shiny product in fruits and vegetables. Lipid-based films are often supported on a polymer structure matrix, usually a polysaccharide, to provide mechanical strength.

\section{Film/Coating-Forming Mechanisms}

Films can be formed via several processes, depending on the starting material and can be obtained by extrusion, 
co-extrusion, spreading, casting, roll coating, drum coating, pan coating or laminating techniques. Edible coatings, on the other hand, are mainly applied using spraying, drum coating, spray fluidization, pan coating or falling film techniques [10].

The film-forming mechanisms of biopolymers include intermolecular forces such as covalent bonds (e.g., disulfide bonds and cross-linking) and/or electrostatic, hydrophobic or ionic interactions. For the resulting films or coatings to be edible, the film-forming mechanism involved in fabrication should be an appropriate food process, namely $\mathrm{pH}$ modification, salt addition, heating, enzymatic modification, drying, use of food-grade solvents and addition of other food-grade chemicals. The control of fabrication process conditions is very important because changes in treatment conditions can alter kinetics and reaction mechanisms $[14,15]$.

Han and Gennadios [16] described potential chemical and physical approaches to the modification of film-forming mechanisms by altering film-forming raw materials, varying film-forming processing conditions and applying treatments on formed films (Fig. 1).

As examples, potential chemical methods for modifying film-forming mechanisms of protein-based films include $\mathrm{pH}$ changes, salt addition, heat denaturation, solvent changes, chemical modification of the side chains of peptides, cross-linking, and hydrolysis of peptides [17-19], irradiation of peptides [20] and the addition of foreign proteins.

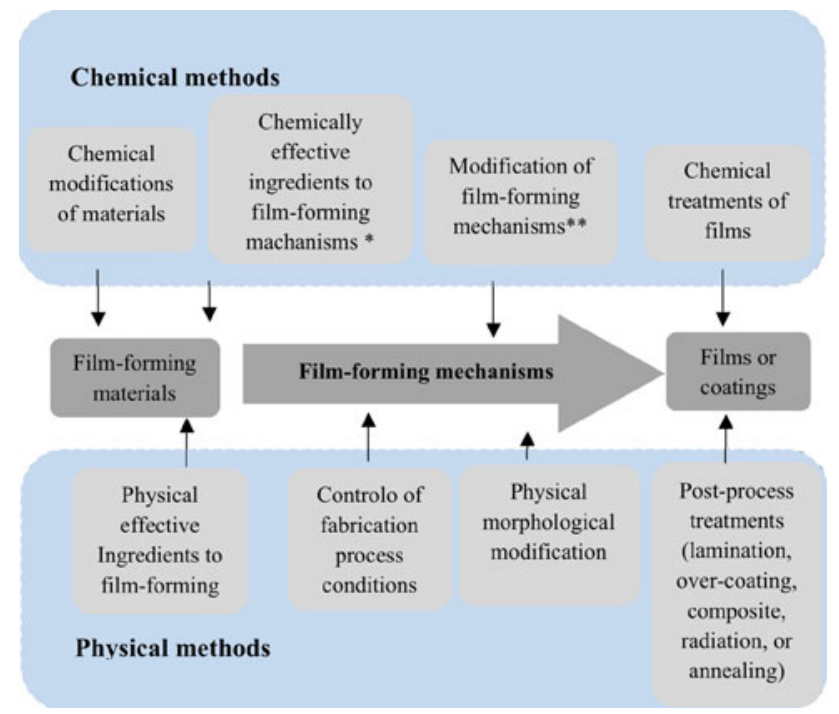

Fig. 1 Methods for modifying the characteristics of edible films and coatings. * Indicates the addition of chemically or physically active ingredients, which may enhance or interfere with the film-forming mechanisms; ** includes any chemical cross-linking, chemical substitution of side chains to create hydrophobic interaction or electrostatic interactions, and other extra mechanisms caused by chemical modifications (adapted from Han and Gennadios [16])
For polysaccharide-based films, several chemical modifications are available, including salt addition, solvent changes, heat gelatinization, $\mathrm{pH}$ changes, chemical modification of hydroxyl groups, cross-linking of polysaccharides, hydrolysis of polysaccharides and the addition of foreign polysaccharides [21-24].

Physical modifications of edible films and coatings include lamination, formation of composites, addition of particles or emulsions, perforation, over-coating, annealing heat curing, orientation, radiation, ultrasound treatment and electric field treatments [25-30]. Mechanical or physicochemical properties of films can be improved e.g., by application of extrusion or promotion of reaction between film components [30]. In particular, the application of electric field treatments to film- and coating-forming solutions holds promise in tailoring films' and coatings' properties in unique ways and will be dealt with below in a greater detail.

In the specific case of edible coatings, also the knowledge of the surface properties of the coating-forming solutions is crucial for the characterization of their performance, and therefore a special word on this subject is due here.

\section{Surface Properties}

The effectiveness of edible coatings depends primarily on the control of the wettability (Ws) of the coating solutions [31]. They must wet and spread on the surface of the food product, and upon drying, they must form a film that has the adequate properties and durability. The coating process involves wetting of the food product by the coating solution and the possible penetration of the solution into its skin [32]. Also, the surface energy or surface tension of the food product is a controlling factor in the process that involves wetting and coating of surfaces [33]. The determination of surface tension usually involves measuring the contact angles that several standard liquids make with that surface. The surface energy of the solid surface is then related to the surface tensions of the liquids and the contact angles. This method invokes an estimation of the critical surface tension of the surface of the solids studied, by extrapolation from the Zisman plot [34].

The wettability is obtained by determining the values of the spreading coefficient $(W s)$ and the works of adhesion $(W a)$ and cohesion $(W c)$. The surface tension of the coating solution is measured by the pendant drop method using the Laplace-Young approximation [7]. The contact angle $(\theta)$ of a liquid drop on a solid surface is defined by the mechanical equilibrium of the drop under the action of three interfacial tensions: solid-vapor $\left(\gamma_{\mathrm{SV}}\right)$, solid-liquid $\left(\gamma_{\mathrm{SL}}\right)$ and liquid-vapor $\left(\gamma_{\mathrm{LV}}\right)$ (Fig. 2). The equilibrium 
spreading coefficient $(W s)$ is defined by Eq. 1 [35] and can only be negative or zero.

$W s=W a-W c=\gamma_{S V}-\gamma_{L V}-\gamma_{S L}$

where $W a$ and $W c$ are the works of adhesion and cohesion, defined by Eqs. 2 and 3, respectively:

$$
\begin{aligned}
& W a=\gamma_{L V}-\gamma_{S V}-\gamma_{S L} \\
& W c=2 \cdot \gamma_{L V}
\end{aligned}
$$

Choi et al. [36] studied the wettability of chitosan coating solutions on 'Fuji' apple skin using the Du Nouyring method and the sessile-drop method. The 'Fuji' apple skin surface presents a critical tension of $18.7 \mathrm{mN} \mathrm{m}^{-1}$. Ribeiro et al. [37] obtained a similar value for the critical surface tension of strawberries $\left(18.84 \mathrm{mN} \mathrm{m}^{-1}\right)$, which were reported to have a superficial tension of $28.94 \mathrm{mN} \mathrm{m}^{-1}$, with polar and dispersive components of 5.95 and $22.99 \mathrm{mN} \mathrm{m}^{-1}$, respectively. In both cases, to enhance the wettability of the coating solutions, Tween 80 was added, reducing the superficial tension of the liquid and thus increasing the spreading coefficient.

Casariego et al. [38] determined the effects of the concentrations of plasticizers, Tween 80 and chitosan on the wettability of chitosan-based edible coatings in view of their application on tomato and carrot. They present the superficial tensions of tomato and carrot as being 28.71 and $26.48 \mathrm{mN} \mathrm{m}^{-1}$, respectively. The increase in chitosan concentration and the presence of glycerol or sorbitol as plasticizers decreased the values of wettability and adhesion coefficients. The best experimental values of wettability were obtained for coatings produced with $1.5 \%(\mathrm{w} / \mathrm{v})$ of chitosan and $0.1 \%(\mathrm{w} / \mathrm{w})$ of Tween 80 .

A good choice of the coating formulation is essential for the durability and maintenance of the coating on the food products, and the determination of wettability together with the study of the surface properties of the products is fundamental for the correct formulation and application of edible coatings. Further work needs to be performed

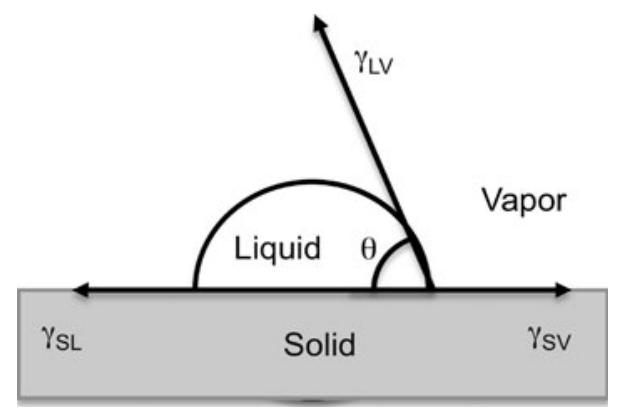

Fig. 2 Sessile drop, where contact angle $(\theta)$ and the three interfacial tensions $\left(\gamma_{L V}\right.$ liquid-vapor, $\gamma_{S V}$ solid-vapor and $\gamma_{S L}$ solid-liquid) are shown aiming at understanding the influence of the application method and temperature in coatings' performance [7].

\section{Electric Fields Processing}

Processing technologies utilizing electrical energy directly into foods are currently being used at a commercial scale for producing an extensive range of food products. Further research in this area will allow the opportunity to create new and value-added food products with enhanced quality attributes, converging with actual consumers preferences [39-41].

Electric fields processing (e.g., ohmic heating) is based on the passage of electrical current through a food product that has an electrical resistance. The electrical energy is thus converted to heat. Instant heating occurs, its magnitude depending on the intensity of the current passing through the food material. One possible device to apply electric fields is illustrated in Fig. 3. For this type of system, the electric field strength can be varied by adjusting the electrode gap or the applied voltage; one of the most important factors governing the behavior of these systems is the electrical conductivity of the product being heated and its dependence on temperature [42]. If the product consists of more than one phase such as in the case of a mixture of liquid and particulates, the electrical conductivity of all the phases has to be considered. The electrical conductivity increases with rising temperature for most food materials, suggesting that ohmic heating becomes more effective as temperature increases, but this could result in runaway heating. Differences in the electrical resistance and its temperature dependence between the two phases can complicate the heating characteristics of the system. Electrical conductivity is influenced by the ionic content being possible to adjust the electrical conductivity

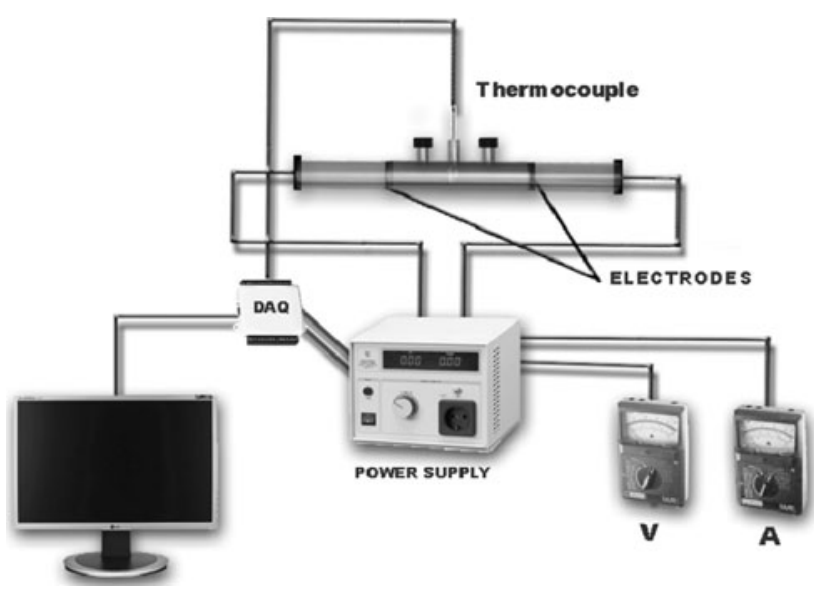

Fig. 3 Schematic diagram showing the device used to perform electric field heating 
of a product by adding electrolytes (e.g., salts) to manipulate the heating patterns and to improve the effectiveness of ohmic heating [42].

Electric fields heating has gained importance because the products are of a superior quality to those processed by conventional technologies [43-45]. Moreover, the heater assembly can be incorporated into a complete product sterilization or cooking process. Among the advantages claimed for this technology are uniformity of heating and improvements in quality, with minimal structural, nutritional or organoleptic changes [46].

The application of electric fields has also been addressed by researchers in the area of edible films and coatings, and there are works showing that the application of electric fields promotes a significant improvement of properties such as transport and mechanical [27-30]. Until the present moment, only two methodologies have been tested, which are briefly described below: (1) the application of the electric field to the film-forming solutions with subsequent drying $[27,47]$ and (2) the application of the electric field during the drying process $[28,30]$. The results of the application of these methodologies are described in the subsequent parts of this text.

\section{Application of Electric Fields to the Film-Forming Solutions Followed by Drying}

Souza et al. [27] studied the effect of electric field strength on transport properties of chitosan coatings through the application of a moderate electric field to chitosan solutions. These solutions were subsequently cast on a surface and dried under controlled humidity and temperature conditions. Chitosan solution samples were treated in an ohmic heater using an alternating current source of $50 \mathrm{~Hz}$ at four different electric field strength values (from 50 to $200 \mathrm{~V} \mathrm{~cm}^{-1}$ ) with a 2 -cm gap between the electrodes. In all cases, an increase in temperature from room temperature up to $60{ }^{\circ} \mathrm{C}$ was observed. Temperatures were monitored using a type- $\mathrm{K}$ thermocouple, placed at the geometrical center of the chamber though the available opening. A data logger was employed to record, continuously and simultaneously, current intensity, voltage and temperature. The thermal history of the samples, until temperature stabilization, was monitored by the introduction of a thermocouple connected to the data acquisition system previously described; this treatment was used as control in order to discard the temperature effects and to evaluate only the effects of electric field.

Pereira et al. [47] studied the effect of electrical fields application to WPI solutions and characterized them in terms of their physical and structural properties, comparing with films obtained using conventional heating methods. The effects of heating (conventional and ohmic) on thermal aggregation of whey proteins, before drying and film formation, were also evaluated in an attempt to provide insight into the mechanisms that may be influencing the observed changes in films' properties. Ohmic heating treatments were performed in a concentrical cylindrical glass tube of $30 \mathrm{~cm}$ total length and an inner diameter of $2.3 \mathrm{~cm}$, with two inox electrodes isolated at each edge with Teflon caps. For the experiments, a 10-cm gap between the electrodes (defining the treatment chamber) was used, and the supplied voltage ranged from 20 to $220 \mathrm{~V}$. For $30 \mathrm{~min}$ of holding at $85{ }^{\circ} \mathrm{C}$, a nominal electrical field of $10 \mathrm{~V} \mathrm{~cm}^{-1}$ was applied. The supplied voltage, and consequently temperature, was controlled through the use of a rheostat (Chuan Hsin, Taiwan) connected to the monophasic alternate current supply system $(231 \mathrm{~V}, 50 \mathrm{~Hz})$. During the experiments, the nominal electric field was varied through the rheostat to adjust the supplied voltage and simulate the thermal history of samples observed during conventional heating experiments. A close coincidence of the temperature profiles during the sample's heating phase, in both conventional and ohmic treatments, was a necessary condition to evaluate the nonthermal effects of ohmic heating.

\section{Application of Electric Fields During Drying}

Garcia et al. [30] studied the effects of applying an electric field on films during their drying process. The electric field was applied parallel to the surface of the film in order to obtain axially oriented films. The electrically treated films were obtained by casting in a house-built cell with a positive and negative electrode, placed inside an oven at $60{ }^{\circ} \mathrm{C}$. The electrodes were set into acrylic plates filled with different film-forming solutions and connected to a $12-\mathrm{V}$ power supply. Control films were obtained by casting and dried at $60{ }^{\circ} \mathrm{C}$ in an oven until constant weight.

Lei et al. [28] studied the different effects of ohmic heating and water bath heating on the production of a protein-lipid film from soybean milk. A home-made square cell, made of Teflon, was employed in which the proteinlipid film was formed. Two titanium electrodes with Teflon pressure caps were placed at two opposite sides of the system. Temperature was monitored using a type-K thermocouple connected to a data acquisition system. The soybean milk was heated using a low-frequency alternating current from the public utility supply $(50 \mathrm{~Hz}, 220 \mathrm{~V})$. The temperature of soybean milk was controlled within $85 \pm 3{ }^{\circ} \mathrm{C}$. After 7-8 min, the first film was formed on the surface. An L-shaped glass rod was slipped under the film and then gently lifted, resulting in a sheet film hung upon the rod. The film sheet was drained for a few seconds and then hung to air dry (ambient dehydration) for $1 \mathrm{~min}$ before 
being taken down from the rod and tightly wrapped with transparent plastic film.

\section{Influence of Electric Fields in Edible Coatings/Films Structure and Properties}

Edible films and coatings are designed to function as a barrier to water vapor, gas $\left(\mathrm{O}_{2}\right.$ and $\left.\mathrm{CO}_{2}\right)$, flavor and aroma, thus improving food quality and increasing its shelf life [20].

Both $\mathrm{O}_{2}$ and $\mathrm{CO}_{2}$ permeabilities are important when respiration or oxidation reactions could affect quality of the food. Mechanical properties of edible coatings/films are important in food protection, reducing bruising and split, protecting food integrity. Film solubility is also an important property: in some cases, a water-insoluble film or coating is preferred in order to provide water resistance and improve food integrity [20,48]; in other cases, edible films with high water solubility may be required [49].

\section{Structure Characterization}

Scanning electronic microscopy (SEM) and X-ray diffraction (XRD) are frequently used to characterize edible films' structure [5, 50]. SEM may be used to evaluate film homogeneity, layer structure, pores and cracks, surface smoothness and thickness, while XRD is mainly used to evaluate the degree of crystallinity of the films.

Souza et al. [29] showed that when chitosan filmforming solutions were submitted to an electric field, chitosan films presented crystals in their structure, evidencing the occurrence of morphological influences from the treatment. SEM analyses indicated that the electric treatment significantly changed the films toward a more regular structure, which may presumably be reflected on the changes observed in the surface morphology of the film. The surface of the composite control films (Fig. 4a1) appeared more homogeneous than that of the treated films (Fig. 4c1 and d1). Also, a structure with more regular layers was detected in the case of the film produced with the electrically treated film-forming solutions, as can be observed in the cross-section images of Fig. $4 \mathrm{c} 2$ and $\mathrm{d} 2$. The development of films with a uniform and compact layer can be an important achievement toward the improvement of various film properties, such as their permeability to gases. The search for homogeneous structures thus becomes a target of research involving edible films. In this perspective, the application of electric fields may provide an interesting solution. In the same line, Garcia et al. [30] showed that the surface morphologies of films were influenced by the preparation method, indicating that the application of an electric field during drying was an influencing factor; in this work, control films exhibited a more homogeneous, smoother surface than that of treated films.

Crystallinity measures the extent of organization of the molecules in a polymer. Polymer properties that affect crystallinity include the structural regularity of the polymer chains, polymer chain mobility (which allows variable conformation), the repeated presence of side chains (which engage in intermolecular bonding) and the absence of bulky side chains (which interfere with the crystal lattice formation). The mass transfer of gas in a semi-crystalline polymer is primarily a function of the amorphous phase, because the crystal line phase is usually assumed to be impermeable. As the percent crystallinity of a polymer increases, the oxygen permeability decreases. The degree to which oxygen permeability is affected is thus highly dependent on polymer structure [22].

Usually, polymers possess a high degree of crystallinity, forming an organized structure that has good mechanical properties [51]. XRD can be used to track recrystallization of film polymers during storage. In the case of starch-based films, peak width decreased slightly and peak intensities increased, indicating a growth in crystallite size corresponding to a slow recrystallization process. XRD patterns of composite films generally represent a mixture of component features in which the characteristic peaks of individual components can be identified [52].

Souza et al. [29] showed that chitosan coating treated with an electric field of $200 \mathrm{~V} \mathrm{~cm}^{-1}$ developed a more crystalline structure, showing an increased value of CI $(15.3 \%)$. This indicated that during the moderate electric field treatment, a structure with a different XRD pattern was developed. This may be attributed to the fact that the chitosan chains with higher degree of deacetylation are more flexible. Flexible chains will facilitate hydrogen bonding and consequently crystallinity formation in the film. The results indicated that the application of a moderate electric field to the film-forming solutions had significant effects on the crystallinity index (CI), which were confirmed by DSC: those films treated with electric fields featured higher CI values. The (CI) is defined using the following equation:

$\mathrm{CI}=\left(I_{110}-I_{\mathrm{am}}\right) / I_{110}$

where $I_{110}$ is the maximum intensity $\left(2 \theta, 20^{\circ}\right)$ of the (110) lattice diffraction and $I_{\mathrm{am}}$ is the intensity of the amorphous diffraction $\left(2 \theta, 16^{\circ}\right)$ [29].

Wan et al. [53] demonstrated that the X-ray pattern of a chitosan membrane has two characteristic peaks located at $2 \theta$ of about $10.2^{\circ}$ and $20.2^{\circ}$. It is known that chitosan always contains bound water (5\%), even if it has been extensively dried. The incorporation of bound water molecules into the crystal lattice, commonly termed hydrated crystals, 
Fig. 4 SEM microphotographs of chitosan films. Surfaces morphologies: $\left(\mathbf{a}_{1}\right)$ control (no heating), $\left(\mathbf{b}_{1}\right)$ conventional heating, $\left(\mathbf{c}_{1}\right)$ electric field heating at $100 \mathrm{~V} \mathrm{~cm}^{-1},\left(\mathbf{d}_{1}\right)$ electric field heating at $200 \mathrm{~V} \mathrm{~cm}^{-1}$. Cross-sections from chitosan films: $\left(\mathbf{a}_{2}\right)$ control, $\left(\mathbf{b}_{2}\right)$ conventional heating, $\left(\mathbf{c}_{2}\right)$ electric field heating at $100 \mathrm{~V} \mathrm{~cm}^{-1},\left(\mathbf{d}_{2}\right)$ electric field heating at $200 \mathrm{~V} \mathrm{~cm}^{-1}$
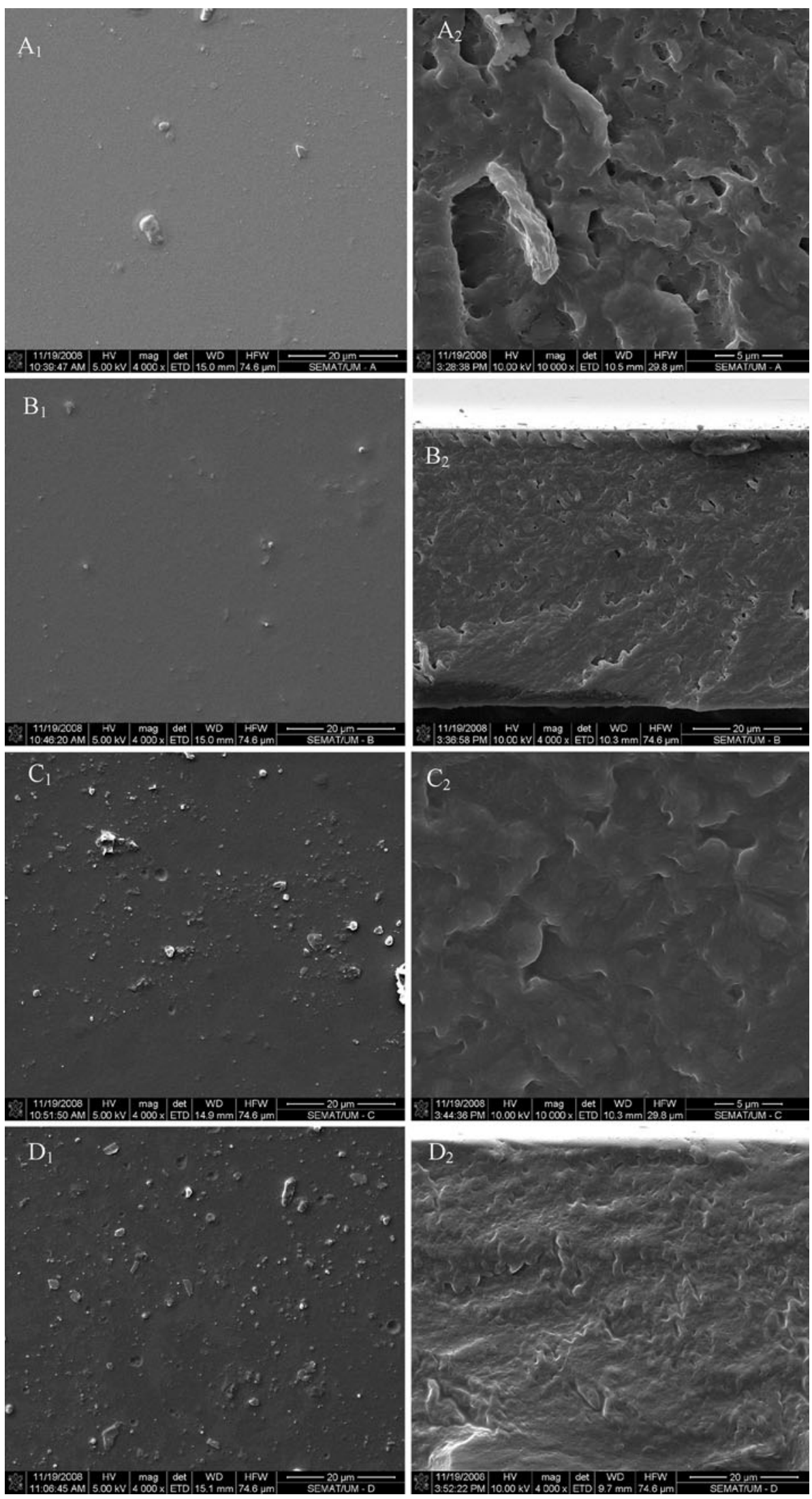
generally gives rise to a predominate polymorphism that can be normally detected by a broad crystalline peak in the corresponding X-ray pattern. Therefore, the crystalline peak centered at around $10^{\circ}$ is attributed to the hydrated crystalline structure of chitosan [52, 54]. Another peak registered near $20^{\circ}$ is reported to be the indication of the relatively regular crystal lattice (110) of chitosan $[53,55]$.

Balau et al. [56] studied the X-ray diffractograms of chitosan films, an almost amorphous structure. They showed that films treated with an electric field of $E=20 \mathrm{kV} \mathrm{cm}^{-1}$ developed a crystalline structure, while the films to which no electric field was applied displayed a significantly lower proportion of crystalline material, showing that the electric field plays an important role in the crystallization process.

Garcia et al. [30] indicated that during film drying under an electric field, a sharp peak at $2 \theta=15^{\circ}$ appeared and developed a structure with a different X-ray diffraction pattern. This structure was more ordered, since the crystallinity index (CI) of chitosan treated film was of $14 \%$ when comparing to the value for untreated films). The application of a moderate electric field to the chitosan filmforming solution had thus a significant effect on the crystallinity index of the film.

Transport Properties: Permeability to Water Vapor, $\mathrm{CO}_{2}$ and $\mathrm{O}_{2}$

Permeability is a steady-state property that describes the extent to which a permeating substance dissolves and then the rate at which it diffuses through a film, with a driving force related to the difference in the concentration of that substance between the two sides of the film [21]. Gas permeabilities of edible films and coatings depend on several factors such as the integrity of the film, the ratio between crystalline and amorphous zones, the hydrophilichydrophobic ratio and the polymeric chain mobility; the interaction between the film-forming polymers and the presence of a plasticizer or other additives are also important factors in film permeability [22]. On the one hand, oxygen is the key factor that might cause food oxidation, inducing several unwanted changes such as odor, color and flavor, as well as nutrients deterioration. Therefore, films providing a proper oxygen barrier can help improving food quality and extending its shelf life [57]. On the other hand, carbon dioxide is formed in some foods due to deterioration and respiration reactions. The $\mathrm{CO}_{2}$ produced has to be removed from the package to avoid food deterioration and/or package destruction [58].

Water vapor permeability (WVP) is an important parameter commonly considered in food packaging. WVP comprises sorption, diffusion and adsorption and is largely governed by the interactions between the polymer and the water molecules [59]. Water permeation through a film usually occurs through the hydrophilic part of the film, thus the relation of the hydrophilic/hydrophobic portions will influence WVP. Polymers with high hydrogen bonding produce films that are susceptible to moisture, while polymers with hydrophobic groups make excellent barriers to moisture. Generally, WVP is also dependant on the pore size of the film [60]. In fact, WVP tends to increase with polarity, degree of unsaturation and degree of ramification of the lipids used (if any), in addition to the effect of the water molecule sorption by the polar part of the film material [61]. Nevertheless, the poor water vapor barrier may in some cases be beneficial since it allows movement of water vapor across the film, thus preventing water condensation, which is a potential source of microbial spoilage [8]. In general, however, WVP should be as low as possible since an edible film or coating should retard moisture transfer between the food and the environment, or between two components of a heterogeneous food product [62].

WVP is usually measured using a variation of the ASTM Standard Method E 96 (ASTM, 1987), known as the "cup method". $\mathrm{CO}_{2}$ permeability can be measured using a modified permeability cell designed such as the one by Gilbert and Pegaz [63].

Gas and water vapor permeabilities of films and coatings can be calculated as shown below [31].

Permeation can be described mathematically by Fick's first law. The flux $(J)$, which is proportional to the concentration gradient, can be defined in one direction as follows:

$J=-D(\partial C / \partial X)$

where $J$ is the flux, the net amount of solute that diffuses through unit area per unit time $\left(\mathrm{g} / \mathrm{m}^{2} \mathrm{~s}\right.$ or $\left.\mathrm{ml} / \mathrm{m}^{2} \mathrm{~s}\right), D$ is the diffusivity constant $\left(\mathrm{m}^{2} / \mathrm{s}\right), C$ is the concentration gradient of the diffusing substance and $X$ is the thickness of the film (m) [31].

Considering as assumptions that (1) the diffusion is in steady state and (2) there is a linear gradient through the film, the flux $(J)$ is given by the following:

$J=D\left(C_{2}-C_{1}\right) / X=Q /(A t)$

where $Q$ is the amount of gas diffusing through the film ( $\mathrm{g}$ or $\mathrm{ml}$ ), $A$ is the area of the film through which the gas diffuses $\left(\mathrm{m}^{2}\right)$ and $t$ is time (s). After application of Henry's law, the driving force is expressed in terms of the differential partial pressure of gas between the two sides of the film and a rearrangement of terms yields the following equation in terms of permeability $(P)$ :

$Q /(A \cdot t)=D \cdot S \cdot\left(p_{2}-p_{1}\right) / X=P \cdot \Delta p / X$

where $S$ is the Henry's law solubility coefficient (mole/Pa), $\Delta p$ is partial pressure difference (between $p_{1}$ and $p_{2}$, which 
are the partial pressure values in each of the sides of the film) of the gas across the film (Pa), and $P$ is the permeability $\left((\mathrm{ml}\right.$ or $\left.\mathrm{g}) \mathrm{m} / \mathrm{m}^{2} \mathrm{~s} \mathrm{~Pa}\right)$. Then, the permeabilities of $\mathrm{O}_{2}, \mathrm{CO}_{2}$ and water vapor can be calculated from the following equation [31]:

$P=Q \cdot X /(A \cdot t \cdot \Delta p)$

Souza et al. [27] showed that WVP of chitosan films decreased (up to $17.3 \%$ ) with the increase in the electric field strength applied to the film-forming solution, for values of $100 \mathrm{~V} \mathrm{~cm}^{-1}$ or higher (Table 1) showing lower WVP values than those of other hydrocolloid-based films reported in the literature $[3,22,56,64,65]$. A positive correlation was found between WVP and the crystallinity of the film. The work of Miller and Krochta [22] also points at the fact that the permeability is highly affected by how closely packed the polymer chains are, thus establishing a direct relationship between the crystallinity of the structure and permeability.

Garcia et al. [30] studied the effect of applying an electric field during drying of films formulated with different concentrations of chitosan and methylcellulose on the microstructure and water-vapor-barrier properties. Electrically treated films exhibited lower WVP values than control samples: WVP decreased by $12 \%$ for chitosan films, and for composite films (chitosan + methylcellulose), this reduction was within the range of $20-29 \%$ as methylcellulose content increased. This result was attributed to the development of a differently ordered structure with the application of an electric field since water vapor permeates preferably through the amorphous zones. These results have shown that the electric field treatment could be a good alternative to improve film flexibility and to increase its water-vapor-barrier properties.
A great amount of work has been performed on the effects of different factors in oxygen $\left(\mathrm{O}_{2} \mathrm{P}\right)$ and carbon dioxide $\left(\mathrm{CO}_{2} \mathrm{P}\right)$ permeability of chitosan films [24].

Souza et al. [27] showed that the samples subjected to electrical field treatments at $100 \mathrm{~V} \mathrm{~cm}^{-1}$ or higher presented reduced values of $\mathrm{O}_{2} \mathrm{P}$ and $\mathrm{CO}_{2} \mathrm{P}$ (reductions of $9.2 \%$ and $3.7 \%$, respectively). This observation was attributed to the fact that film structure was altered (e.g., changes were observed in crystallinity) due to the application of the electric field during the preparation of the film-forming solutions.

\section{Solubility in Water}

Solubility in water is defined as the maximum percentage (by weight) of a substance that will dissolve in a unit volume of water at certain (usually room) temperature. It is an important property, which governs potential applications of these materials to food preservation.

The results observed by Garcia et al. [30] showed that methylcellulose films were completely soluble in water, while control chitosan films had lower solubility values. Composite samples had intermediate water solubilities, which decreased with increasing chitosan proportion. In all cases, electrically treated film samples resulted less soluble than control samples, regardless of chitosan content.

Souza et al. [27] evaluated the effect of electric field strength on solubility in water of chitosan films and showed that the solubility decreases with increasing field strength values for $100 \mathrm{~V} \mathrm{~cm}^{-1}$ or higher. Balau et al. [56] showed that the electric field plays an important role in the crystallization process, which may also interfere in the water solubility of the films. In fact, similarly to what has been reported for gas permeability, the solubility of chitosan
Table 1 Comparison of WVP values of diverse edible films produced without and with electric fields treatment

\begin{tabular}{lll}
\hline Film composition & WVP $\left(\mathrm{gm}^{-1} \mathrm{~s}^{-1} \mathrm{~Pa}^{-1}\right)$ & References \\
\hline Calcium alginate:fructose & $\approx 18 \times 10^{-11}$ & {$[64]$} \\
Calcium alginate:PEG 400 & $\approx 65 \times 10^{-11}$ & {$[64]$} \\
Chitosan (96\% acetylation):glycerol & $30.6 \times 10^{-11}$ & {$[56]$} \\
Chitosan (96\% acetylation) & $24.7 \times 10^{-11}$ & {$[56]$} \\
Starch/chitosan:glycerol & $39.2 \times 10^{-11}$ & {$[22]$} \\
Starch/chitosan:glycerol:ferulic acid & $31.9 \times 10^{-11}$ & {$[22]$} \\
Starch:MC & $20.5 \times 10^{-11}$ & {$[3]$} \\
Starch:MC:soybean oil & $11.7 \times 10^{-11}$ & {$[3]$} \\
Chitosan:Tween 80 & $\approx 160 \times 10^{-11}$ & {$[69]$} \\
Chitosan:Tween 80:oleic acid & $\approx 78 \times 10^{-11}$ & {$[27]$} \\
Chitosan 1.5\% with Tween 80 & $3.69 \times 10^{-11}$ & {$[27]$} \\
Chitosan 1.5\% with Tween 80 at $50 \mathrm{~V} \mathrm{~cm}^{-1}$ & $3.67 \times 10^{-11}$ & {$[27]$} \\
Chitosan 1.5\% with Tween 80 at $100 \mathrm{~V} \mathrm{~cm}^{-1}$ & $3.13 \times 10^{-11}$ & {$[27]$} \\
Chitosan 1.5\% with Tween 80 at $150 \mathrm{~V} \mathrm{~cm}^{-1}$ & $3.11 \times 10^{-11}$ & {$[27]$} \\
Chitosan 1.5\% with Tween 80 at $200 \mathrm{~V} \mathrm{~cm}^{-1}$ & $3.04 \times 10^{-11}$ & \\
\hline
\end{tabular}


Fig. 5 Mechanical properties of chitosan films; (filled square) control (filled square) conventional heating (filled square) electric fields $100 \mathrm{~V} \mathrm{~cm}^{-1}$, (filled square) electric fields $200 \mathrm{~V} \mathrm{~cm}^{-1}$. Different letters in the bars correspond to statistically different samples $(p<0.05)$ (adapted from Souza et al. [29])

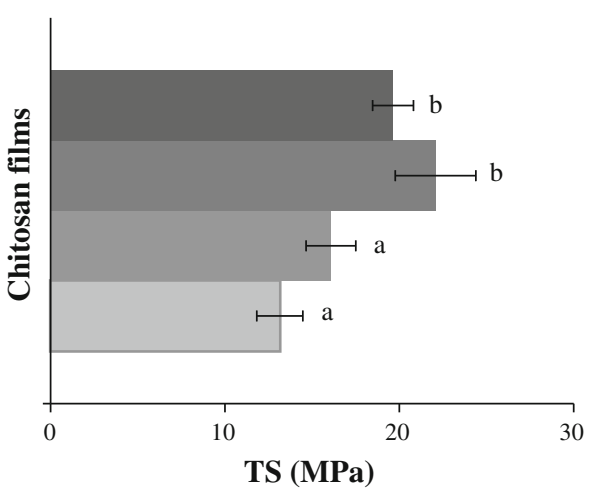

films has been associated with the crystallinity of the sample; a high crystallinity contributes to a higher insolubility [22].

Lei et al. [28] showed that during the rehydration process, the amount of water absorbed had a quick increase during the first $10 \mathrm{~min}$, when a maximum was reached, for both heating methods (ohmic and water bath heating). However, the maximum amount of water absorbed by the protein-lipid film was larger for the film formed by ohmic heating than for the film formed by water bath heating, meaning that the rehydration rate was higher in the first case. This change was probably caused by a different degree of cellular and structural destruction of the proteinlipid film, once it has been described that the degree of rehydration is dependent on the degree of cellular and structural disruption [64].

\section{Mechanical Properties}

Tensile strength (TS) and elongation-at-break $(E)$ are frequently used to characterize the mechanical properties of films; TS is the maximum tension supported by the film until the moment it collapses. $E$ is a measure of the flexibility of the film and can be considered as a characteristic that defines the ability of the film to deform in place before it collapses.

TS was expressed in MPa and is calculated by dividing the maximum load $(N)$ by the cross-sectional area $\left(\mathrm{m}^{2}\right)$. Percent elongation $(E)$ at break is determined by dividing the length of the samples at the moment of rupture by the initial gauge length of the samples and multiplying by 100 . These measurements are important once the mechanical properties of films or coatings depend on the filmogenic nature of the material used, which is directly related to its structural cohesion [20]. Multiple factors, such as film composition, temperature, relative humidity and storage time, affect tensile properties. Generally, the addition of plasticizers leads to a decrease in TS and an increase in $E[49,66]$.

Souza et al. [29] showed that the application of an electric field (100 and $\left.200 \mathrm{~V} \mathrm{~cm}^{-1}\right)$ to chitosan filmforming solutions caused significant differences in TS $(9 \%$ increase) and $E$ (18\% increase), as shown in Fig. 5. This behavior can be related with the higher crystallinity pattern of the films subjected to the electric field treatment. Park et al. [67] stated that the increase in the values of TS and $E$ for chitosan films is related with the deacetylation degree of the sample. Chen et al. [68] and Ziani et al. [69] mentioned that those results were due to the higher crystallinity of chitosan films. The polymer chain of chitosan with a higher degree of deacetylation was reported to be more mobile, and this increased mobility was in turn related with an easier formation of inter- or intra-chain hydrogen bonds. This leads to a higher crystallinity that reduces the absorption of water molecules and produces an increase in TS [69]. In general, the crystallinity of films is directly related with increased intermolecular forces, thus increasing the rigidity and brittleness of the film [70].

Garcia et al. [30] showed that electrically treated samples exhibited higher $E$ values, indicating that the electric treatment allowed the alignment of the chains in the field direction, facilitating their stretching and thus increasing their flexibility.

\section{Research Prospects}

The application of electric fields to film/coating-forming solutions has been shown to significantly affect several properties of the films/coatings. The extent to which such properties are affected has shown dependence on the strength of the electric field applied. This means that it is possible to tailor the films/coatings properties by subjecting them to an electric field of controlled magnitude.

The application of electric field to edible films has been used essentially during the production of the film-forming solution and/or during the drying process. In the first case, the electric field leads to a change in the solution microstructure affecting film properties. In the second case, the film microstructure is changed, but also a polymer chain orientation is provided to the film. This is based in the wellknown effects of mechanical orientation (e.g., through 
stretching) of plastic films that improves e.g., gas permeability, optical and mechanical properties [71].

In practice, the changes in the film properties induced by the application of the electrical field may translate into an improved shelf life of the products due to reduced water loss (calculated on the basis of the lower WVP) and reduced $\mathrm{O}_{2}$ and $\mathrm{CO}_{2}$ exchanges (due to the lower values of $\mathrm{O}_{2} \mathrm{P}$ and $\mathrm{CO}_{2} \mathrm{P}$ ), which will mean a slower metabolism e.g., in fruits and vegetables.

The application of electric fields may thus provide a novel method for the production of films with tailored properties; however, further research is needed for a clearer understanding of the importance of these changes on real food systems applications.

Acknowledgments Author B.W.S. Souza is the recipient of a fellowship from the Coordenação de Aperfeiçoamento de Pessoal de Nível Superior (CAPES, Brazil), author M.A. Cerqueira is recipient of a fellowship from the Fundação para a Ciência e a Tecnologia (FCT, Portugal) (SFRH/BD/23897/2005).

\section{References}

1. Bourtomm T (2008) Edible films and coatings: characteristics and properties. Int Food Res J 15(3):1-12

2. Krochta JM (2002) Proteins as raw materials for films and coatings: definitions, current status, and opportunities. In: Gennadios A (ed) Protein-based films and coatings. CRC Press LLC, Florida

3. Bravin B, Peressini D, Sensidoni A (2006) Development and application of polysaccharide-lipid edible coating to extend shelf-life of dry bakery products. J Food Eng 76:280-290

4. Rooney ML (2005) Introduction to active food packaging technologies. In: Han JH (ed) Innovations in food packaging, vol 5. Elsevier Science \& Technology Books, Amsterdam, pp 63-77

5. Lin D, Zhao Y (2007) Innovations in the development and application of edible coatings for fresh and minimally processed fruits and vegetables. Compr Rev Food Sci Food Saf 6(3): 60-75

6. Rinaudo M (2008) Main properties and current applications of some polysaccharides as biomaterials. Polym Int 57:397-430

7. Guilbert S (1986) Technology and application of edible protective films. In: Mathlouthi M (ed) Food packaging and preservation-theory and practice. Elsevier Applied Science Publishers Co, London

8. Park HJ, Bunn JM, Weller PJ, Vergano PJ, Testin RF (1994) Water vapor permeability and mechanical properties of grain protein-based films as affected by mixtures of polyethylene glycol and glycerin plasticizers. Trans ASAE 37:1281-1285

9. Nieto MB (2009) Structure and function of polysaccharide gumbased edible films and coatings. In: Embuscado ME, Huber KC (eds) Edible films and coatings for food applications, vol 3. Springer, Berlin, pp 57-112

10. Dangaran K, Tomasula PM, Qi P (2009) Structure and function of protein-based edible films and coatings. In: Embuscado ME, Huber KC (eds) Edible films and coatings for food applications, vol 2. Springer, Berlin, pp 24-56

11. Krochta JM (1997) Edible protein films and coating. In: Damadaram S, Paraf A (eds) Food proteins, their applications. Marcel Dekker, Inc, New York, pp 529-549
12. McHugh TH, Krochta JM (1994) Permeability properties of edible films. In: Krochta JM, Baldwin EA, Nisperos-Carriedo M (eds) Edible coatings and films to improve food quality. Technomic Publishing Company, Inc, Lancaster, pp 139-187

13. Bourtoom T (2008) Edible films and coatings: characteristics and properties. Int Food Res J 15(3):237-248

14. Guilbert S, Biquet B (1996) Edible films and coatings. In: Bureau G, Multon JL (eds) Food packaging technology. VCH Publishers, New York

15. Guilbert S, Cuq B, Gontard N (1997) Recent innovations in edible and/or biodegradable packaging materials. Food Addit Contam 14(6):741-751

16. Han JH, Gennadios A (2005) Edible films and coatings: a review. In: Han JH (ed) Innovations in food packaging, vol 15. Elsevier Science \& Technology Books, Amsterdam, pp 239-259

17. Yildirim M, Hettiarachchy NS (1997) Biopolymers produced by cross-linking soybean $11 \mathrm{~s}$ globulin with whey proteins using transglutaminase. J Food Sci 62(2):270-275

18. Rhim JM (1998) Modification of soy protein film by formaldehyde. Korean J Food Sci Technol 30(2):372-378

19. Were L, Hettiarachchy NS, Coleman M (1999) Properties of cysteine-added soy protein-wheat gluten films. J Food Sci 64: 514-518

20. Lacroix M, Ouattara B (2000) Combined industrial processes with irradiation to assure innocuity and preservation of food products-a review. Food Res Int 33(2):719-724

21. Gennadios A, Weller MA, Hanna MA, Fronnig GW (1996) Mechanical and barrier properties of egg albumen film. J Food Sci 61(3):585-589

22. Miller K, Krochta J (1997) Oxygen and aroma barrier properties of edible films: a review. Trends Food Sci Technol 8(7):228-237

23. Micard X, Belamri R, Morel MH, Guilbert S (2000) Properties of chemically and physically treated wheat gluten films. J Agric Food Chem 48:2948-2953

24. Casariego A, Souza BWS, Cerqueira MA, Teixeira JA, Cruz L, Díaz R, Vicente AA (2009) Chitosan/clay films' properties as affected by biopolymer and clay micro/nanoparticles' concentrations. Food Hydrocolloids 23(7):1895-1902

25. Gennadios A, Rhim JW, Handa A, Weller CL, Hanna MA (1998) Ultraviolet radiation affects physical and molecular properties of soy protein films. J Food Sci 63(2):225-228

26. Banejee R, Chen H, Wu J (1996) Milk protein-based edible film mechanical strength changes due to ultrasound process. J Food Sci 61(4):824-828

27. Souza BWS, Cerqueira MA, Casariego A, Lima AMP, Teixeira JA, Vicente AA (2009) Effect of moderate electric fields in the permeation properties of chitosan coatings. Food Hydrocolloids 23:2110-2115

28. Lei L, Zhi H, Zhang Xiujin Z, Takasuke I, Zaigui L (2007) Effects of different heating methods on the production of proteinlipid film. J Food Eng 82:292-297

29. Souza BWS, Cerqueira MA, Martins JT, Casariego A, Teixeira JA, Vicente AA (2010) Influence of electric fields on the structure of chitosan edible coatings. Food Hydrocolloids 24:330-335

30. García MA, Pinotti A, Martino M, Zaritzky N (2009) Electrically treated composite films based on chitosan and methylcellulose blends. Food Hydrocolloids 23:722-728

31. Park HJ (1999) Development of advanced edible coatings for fruits. Trends Food Sci Technol 10:254-260

32. Hershko V, Klein E, Nussinovitch A (1996) Relationship between edible coatings and garlic skin. J Food Sci 61(4): 769-777

33. Karbowiak T, Debeaufort F, Voilley A (2006) Importance of surface tension characterization for food pharmaceutical and packaging products: a review. Crit Rev Food Sci Nutr 46: 391-407 
34. Zisman WA (1964) Contact angle, wettability and adhesion. In: Fowkes FM (ed) Advances in chemistry, vol 43. ACS, Washington, DC, pp 1-51

35. Rulon J, Robet H (1993) Wetting of low-energy surface. In: John B (ed) Wettability. Marcel Dekker, Inc, New York, pp 4-77

36. Choi WY, Park HJ, Ahn DJ, Lee J, Lee CY (2002) Wettability of Chitosan coating solution on 'Fuji' apple skin. J Food Sci 67: 2668-2672

37. Ribeiro C, Vicente AA, Teixeira JA, Miranda C (2007) Optimization of edible coating composition to retard strawberry fruit senescence. Postharvest Biol Technol 44:63-70

38. Casariego A, Souza BWS, Vicente AA, Teixeira JA, Cruz L, Díaz R (2008) Chitosan coating surface properties as affected by plasticizer, surfactant and polymer concentrations in relation to the surface properties of tomato and carrot. Food Hydrocolloids 22:1452-1459

39. Sastry SK, Barach JT (2000) Ohmic and inductive heating. J Food Sci 65(4):42-46

40. Manvell C (1997) Minimal processing of food. Food Sci Technol Today 11(2):107-111

41. Zareifard MR, Ramaswamy HS, Trigui M, Marcotte M (2003) Ohmic heating behaviour and electrical conductivity of twophase food. Innov Food Sci Emerg Technol 4:45-55

42. Ruan R, Ye X, Chen PL, Doona C, Yang T (2004) Developments in ohmic heating. In: Richardson P (ed) Improving the thermal processing of foods. Woodhead Publishing Ltd, Cambridge, pp 224-252

43. Castro I, Teixeira JA, Vicente AA (2003) The influence of field strength, sugar and solid content on electrical conductivity of strawberry products. J Food Process Eng 26:17-29

44. Kim HJ, Choi YM, Yang TCS, Taub IA, Tempest P, Skudder P, Tucker G, Parrott DL (1996) Validation of OH for quality enhancement of food products. Food Technol 50:253-261

45. Parrott DL (1992) Use of OH for aseptic processing of food particulates. Food Technol 45:68-72

46. Skuder PJ (1989) Ohmic heating in food processing. Asian Food J 4:10-11

47. Pereira RN, Souza BWS, Cerqueira MA, Teixeira JA, Vicente AA (2010) Effect of electric fields on protein unfolding and aggregation: influence on edible films formation. Biomacromolecules. doi:10.102/bm100681a

48. Sébastien F, Stéphane G, Copinet A, Coma V (2006) Novel biodegradable films made from chitosan and poly(lactic acid) with antifungal properties against mycotoxinogen strains. Carbohyd Polym 65:185-193

49. Guilbert S, Biquet B (1989) Les films et enrobage comestibles. In: L'emballage des denrées alimentaires de grande consommation. Technique et Documentation, Lavoisier April, p 320

50. Lima M, Heskitt BF, Sastry SK (1999) Diffusion of beet dye during electrical and conventional heating at steady-state temperature. J Food Process Eng 24(5):331-340

51. Le Tien C, Millette M, Mateescu MA, Lacroix M (2004) Modified alginate and chitosan for lactic acid bacteria immobilization. Biotechnol Appl Biochem 39:347-354

52. García MA, Pinotti A, Martino MN, Zaritzky NE (2009) Characterization of starch and composite edible films and coatings. In: Embuscado ME, Huber KC (eds) Edible films and coatings for food applications. Springer, Berlin, pp 169-209
53. Wan Y, Wu H, Yu A, Wen D (2006) Biodegradable polylactide/ chitosan blend membranes. Biomacromolecules 7:1362-1372

54. Ogawa K, Yui T, Miya M (1992) Dependence on the preparation procedure of the polymorphism and crystallinity of chitosan membranes. Biosci Biotechnol Biochem 56:858-862

55. Yamamoto A, Kawada J, Yui T, Ogawa K (1997) Conformational behavior of chitosan in the acetate salt: an X-ray study. Biosci Biotechnol Biochem 61:1230-1232

56. Balau L, Lisa G, Popa MI, Tura V, Melnig V (2004) Physicochemical properties of chitosan films. Cent Eur J Chem 2(4): 638-647

57. Sothornvit R, Pitak N (2007) Oxygen permeability and mechanical properties of banana films. Food Res Int 40:365-370

58. Vermeiren L, Heirlings L, Devlieghere F, Debevere J (2003) Oxygen, ethylene and other scavengers. In: Ahvenainen R (ed) Novel food packaging techniques. Woodhead Publishing Limited and CRC Press LLC, Cambridge

59. Nivedita S, Sangaj NS, Malshe VC (2004) Permeability of polymers in protective organic coatings. Prog Org Coat 50:28-39

60. Paramawati R, Yoshino T, Isobe S (2003) Effect of degradable plasticizer on tensile and barrier properties of single plasticizedzein film (Pengaruh degradable plasticizer tunggal terhadap karakteristik film dari zein). J Eng Pertanian 1(1):49-57

61. Gontard N, Duchez C, Cuq JL, Guilbert S (1994) Edible composite films of wheat gluten and lipids: water vapor permeability and other physical properties. Int J Food Sci Technol 2:39-50

62. Gontard N, Guilbert S, Cuq JL (1992) Edible wheat gluten films: influence of the main process variables on film properties using response surface methodology. J Food Sci 57(1):190-199

63. Gilbert SG, Pegaz D (1969) Finding a new way to measure gas permeability. Package Eng 14:66-69

64. Krokida MK, Marinos-Kouris D (2003) Rehydration kinetics of dehydrated products. J Food Eng 57:1-7

65. Letendre M, D’Aprano G, Delmas-Patterson G, Lacroix M (2002) Isothermal calorimetry study of calcium caseinate and whey protein isolate edible films cross-linked by heating and $\gamma$-irradiation. J Agric Food Chem 50:6053-6057

66. Gennadios A, Park HJ, Weller CL (1993) Relative humidity and temperature effects on tensile strength of edible protein and cellulose ether films. Trans ASAE 36:1867-1872

67. Park SY, Marsh KS, Rhim JW (2002) Characteristics of chitosan films as affected by the type of solvent acid. J Food Sci 67: 194-197

68. Chen RH, Lin JH, Yang MH (1994) Relationships between the chain flexibilities of chitosan molecules and the physical properties of their casted films. Carbohyd Polym 24:41-46

69. Ziani K, Oses J, Coma V, Maté JI (2008) Effect of the presence of glycerol and Tween 20 on the chemical and physical properties of films based on chitosan with different degree of deacetylation LWT. Food Sci Technol 41:2159-2165

70. Cervera MF, Heinämäki J, Krogars K, Jörgensen AC, Karjalainen M, Colarte AI, Yliruusi J (2004) Solid-state and mechanical properties of aqueous chitosan-amylose starch films plasticized with polyols. Pharm Sci Technol 5(1): article 15

71. Kirkwan M, Strawbridge J (2003) Plastic in food packaging. In: Coles R, McDowell D, Kirkwan M (eds) Food packaging technology. Blakwell Publishing, CRC-Press, Boca Raton, pp 174-240 